\title{
NOISE REDUCTION AT IMAGE NON CONTRAST CT-SCAN UROGRAPHY WITH USING ITERATIVE RECONSTRUCTION
}

\author{
Saifudin $^{1)}$, Catur Budi Saputra ${ }^{2)}$ \\ ${ }^{1}$ Jurusan Teknik Radiodiagnostik dan Radioterapi, Poltekkes Kemenkes Semarang, Jl. Tirto \\ Agung Pedalangan Banyumanik, Kota Semarang, Jawa Tengah, 50268 \\ ${ }^{2}$ Instalasi Radiologi, RSI Sultan Agung Semarang, Jl. Kaligawe KM. 4, Kota Semarang, \\ Jawa Tengah, 50112
}

E-mail: saifudin.sf89@gmail.com

Submitted: $23^{\text {th }}$ January 2021; Accepted: $7^{\text {th }}$ July 2021

https://doi.org/10.36525/sanitas.2021.2

\begin{abstract}
The CT Scan examination technique that in the last decade is popular in diagnosing urinary stones is NCCT Urography examination. This examination is fast and informative, but this examination has a deficiency that the resulting image has a fairly high noise. Iterative Reconstruction is a method of algorithm reconstruction on CT Scan with the basic principle of estimating data to produce reconstruction image by reducing noise. The purpose of this study was to find out the difference in noise value in the use of Iterative Reconstruction in reducing noise and improving the quality of NCCT Urography image. This research was conducted retrospectively, namely on existing image given iterative reconstruction treatment of $20 \%, 40 \%, 60 \%, 80 \%$ and $100 \%$. Samples in each iterative reconstruction treatment group as many as 10 images. Image is done noise measurement by doing ROI in kidneys, ureter and VU. Data analysis is done by conducting different tests of One Way Anova using SPSS Software. The results showed that there was a significant difference in noise value after it was done Iterative Reconstruction. Noise decreased as the percentage of used Iterative Reconstruction increased in NCCT Urography image. In the use of Iterative Reconstruction percentage of $100 \%$ obtained the lowest average noise value of 9.11. The use of Iterative Reconstruction can reduce noise in NCCT Urography image by $9.386 \%$ compared to Filtered Back Projection (FBP). Iterative reconstruction is able to reduce noise and improve the image quality of NCCT Urography
\end{abstract}

Keywords: Iterative Reconstruction, NCCT Urography, Noise

This is an open access journal, and articles are distributed under the terms of the Creative Commons Attribution-Non Commercial-Share Alike 4.0 License, which allows others to remix, tweak, and build upon the work non-commercially, as long as appropriate credit is given and the new creations are licensed under the identical terms.

C2021 Sanitas

Saifudin,Catur Budi $S \mid 15$ 
SANITAS: JURNAL TEKNOLOGI DAN SENI KESEHATANI

\title{
PENGURANGAN NOISE PADA CITRA CT-SCAN UROGRAFI NON KONTRAS DENGAN MENGGUNAKAN REKONSTRUKSI ITERATIVE
}

\begin{abstract}
ABSTRAK
Teknik pemeriksaan CT Scan yang dalam satu dekade terakhir populer dalam mendiagnosis batu saluran kemih adalah pemeriksaan NCCT urography. Pemeriksaan ini cepat dan informatif, akan tetapi pemeriksaan ini memiliki kekurangan yaitu citra yang dihasilkan memiliki noise yang cukup tinggi. Rekonstruksi Iterative merupakan metode rekonstruksi algoritma pada CT Scan dengan prinsip dasar melakukan estimasi data untuk menghasilkan citra rekonstruksi dengan mengurangi noise. Tujuan penelitian ini adalah mengetahui perbedaan nilai noise pada penggunaan Rekonstruksi Iterative dalam menurunkan noise dan meningkatkan kualitas citra NCCT urography. Penelitian ini dilakukan secara retrospektif, yaitu pada citra yang sudah ada diberikan perlakuan Rekonstruksi Iterative 20\%, 40\%, 60\%, 80\% dan 100\%. Sample pada masing-masing kelompok perlakuan Rekonstruksi Iterative sebanyak 10 citra. Citra dilakukan pengukuran noise dengan melakuikan ROI pada Ginjal, Ureter dan VU. Analisis data dilakukan dengan melakukan uji beda One Way Anova menggunakan Software SPSS. Hasil penelitian menunjukkan bahwa terdapat perbedaan yang bermakna nilai noise setelah dilakukan Rekonstruksi Iterative. Noise mengalami penurunan seiring dengan peningkatan persentase Rekonstruksi Iterative yang digunakan pada citra NCCT urography. Pada penggunaan persentase Rekonstruksi Iterative $100 \%$ didapatkan nilai rata-rata noise yang paling rendah yaitu 9,11. Penggunaan Rekonstruksi Iterative dapat mereduksi noise pada citra NCCT urography sebesar 9,386\% dibandingkan dengan Filtered Back Projection (FBP). Rekonstruksi Iterative mampu menurunkan noise dan meningkatkan kualitas citra NCCT urography.
\end{abstract}

Kata Kunci: Rekonstruksi Iterative, NCCT Urography, Noise

\section{PENDAHULUAN}

Seiring dengan perkembangan tekologi di dunia kesehatan terutama pada bidang Radiologi dan Imaging. Pelayanan radiologi dituntut untuk dapat memberikan pelayanan diagnostik yang cepat, tepat dan efisien. Salah satu pemeriksaan radiologi yang cepat dalam proses pemeriksaannya adalah CT Scan. Teknik pemeriksaan CT Scan yang dalam satu dekade terakhir populer adalah pemeriksaan CT Scan urografi tanpa menggunakan kontras media dalam mendiagnosis batu saluran kemih ${ }^{1}$. Pemeriksaan ini disebut juga dengan atau CT Scan urografi non kontras atau Non Contrast Computed Tomography Urography (NCCT urography) ${ }^{2}$. NCCT urography mampu menghasilkan resolusi citra yang baik dengan waktu pemeriksaan yang cepat ${ }^{3}$. NCCT urography dalam mendiagnosis batu saluran kemih memiliki sensitivitas sebesar 97,7\%, spesifitas sebesar 100\% dan False negative sebesar $2 \%{ }^{4,5}$.

Kelebihan pemeriksaan NCCT urography ini adalah dapat dilakukan langsung pada pasien tanpa memerlukan puasa ataupun urus-urus, dilakukan tanpa injeksi media kontras terutama pada pasien dengan kadar Kretainin tinggi $(\geq 2,0 \mathrm{mg} / \mathrm{dl})$, selain itu pemeriksaan 
SANITAS: JURNAL TEKNOLOGI DAN SENI KESEHATANI

ini informatif dalam menampilkan batu non kalsifikasi (batu luscent) ${ }^{4,6}$. Kelemahan dari NCCT urography adalah citra yang dihasilkan memiliki tingkat noise yang tinggi ${ }^{7}$. Noise atau derau adalah fluktuasi (standar deviasi) nilai CT number pada jaringan atau materi yang homogen ${ }^{8}$. Noise akan mempengaruhi kontras resolusi (ketajaman citra), semakin tinggi noise maka kontras resolusi akan menurun ${ }^{9,10}$. Perkembangan teknologi CT Scan saat ini memungkinkan untuk meminimalisir atau mengurangi noise dan meningkatkan kualitas citra adalah dengan menggunakan Rekonstruksi Iterative ${ }^{11,12}$.

Penelitian ini dilakukan dengan menggunakan citra NCCT urography yang sudah ada di Workstation kemudian dilakukan post processing dengan menggunakan Rekonstruksi Iterative. Penelitian ini bertujuan untuk mengetahui perbedaan nilai noise pada penggunaan Rekonstruksi Iterative dalam mengurangi noise citra NCCT urography guna menghasilkan citra yang memiliki kontras resolusi (ketajaman citra) yang optimal.

\section{METODE PENELITIAN}

\section{Desain Penelitian}

Jenis penelitian ini adalah penelitian quasi eksperimen dengan rancangan penelitian post test design. Pemilihan rancangan penelitian ini bertujuan untuk mengetahui adanya perubahan setelah perlakuan (post test) pada kelompok perlakuan. Subjek penelitian adalah citra NCCT urography. Penelitian ini menggunakan teknik purposive sampling yaitu merupakan teknik dalam menentukan sampel dengan pertimbangan tertentu sesuai dengan tujuan penelitian yang dikehendaki ${ }^{13}$. Penghitungan jumlah minimal sampel setiap kelompok yang diperlukan pada penelitian ini diestimasikan berdasarkan rumus Lemeshow ${ }^{14}$. Sampel pada penelitian ini adalah 50 citra NCCT urography dengan masing-masing kelompok perlakuan Rekonstruksi Iterative sebanyak 10 citra (10 sample terpilih kemudian dilakukan Rekonstruksi Iterative 20\%, 40\%, 60\%, 80\% dan $100 \%)$.

\section{Metode Pengumpulan Data}

a. Mengidentifikasi citra NCCT urography dengan kasus batu saluran kemih pada pesawat MSCT Scan. 
SANITAS: JURNAL TEKNOLOGI DAN SENI KESEHATANI

b. Menyembunyikan atau menonaktifkan informasi data identitas pasien pada sampel terpilih.

c. Melakukan post processing citra dengan melakukan Rekonstruksi Iterative 20\%, 40\%, 60\%, 80\% dan 100\%. Pesawat CT Scan yang digunakan daam penelitian ini adalah Merk General Electric dengan Tipe Optima CT660.

d. Melakukan pengukuran noise pada citra NCCT urography dengan menggunakan Region Of Interest (ROI) seluas $3 \mathrm{~mm}^{2}$ pada citra di monitor pesawat MSCT Scan ${ }^{15}$. Pengukuran noise dilakukan pada anatomi citra Ginjal, Ureter dan Kandung Kemih. Hasil Pengukuran noise berupa skala data rasio yang langsung muncul di monitor.

e. Data hasil pengukuran dicatat dalam tabel untuk selanjutnya dilakukan analisis.

\section{Metode Analisis Data}

Analisis data dilakukan dengan menggunakan data tabel Microsoft Excel dan menggunakan Software SPSS (One Way Anova).

\section{HASIL DAN PEMBAHASAN}

Berdasarkan hasil penelitian dengan melakukan pengukuran ROI pada 50 sample citra (10 sample terpilih kemudian dilakukan Rekonstruksi Iterative 20\%, 40\%, 60\%, 80\% dan $100 \%$ ), maka didapatkan rerata hasil noise yang ditampilkan dalam tabel sebagai berikut :

Tabel 1 Hasil Rerata Pengukuran Noise pada citra NCCT Urography dengan Rekonstruksi Iterative

\begin{tabular}{lcccc}
\hline \multicolumn{2}{l}{ Perlakuan } & Ginjal & $\begin{array}{c}\text { Rerata Noise pada Organ } \\
\text { Ureter }\end{array}$ & VU \\
\hline X1 & $20 \%$ & 14,046 & 12,278 & 13,779 \\
X2 & $40 \%$ & 13,144 & 11,744 & 12,565 \\
X3 & $60 \%$ & 11,957 & 10,490 & 11,503 \\
X4 & $80 \%$ & 10,003 & 10,117 & 10,165 \\
X5 & $100 \%$ & 8,519 & 9,391 & 9,108 \\
\multicolumn{2}{l}{$\boldsymbol{p}$ value } & $\mathbf{0 , 0 0 1}$ & $\mathbf{0 , 0 0 1}$ & $\mathbf{0 , 0 0 1}$ \\
\hline
\end{tabular}

Data hasil pengukuran selanjutnya dilakukan analisis anova untuk menguji perbedaan noise. Hasil analisis anova perbedaan nilai noise setelah dilakukan Rekonstruksi Iterative pada citra NCCT urography ditunjukkan pada tabel berikut : 
SANITAS: JURNAL TEKNOLOGI DAN SENI KESEHATANI

Tabel 2 Hasil Analisis Anova Perbedaan Nilai Noise setelah dilakukan Rekonstruksi Iterative pada Citra NCCT Urography

\begin{tabular}{lcccc}
\hline \multicolumn{1}{c}{ Perlakuan } & N & Mean & SD & p value \\
\hline X1 $(20 \%)$ & 10 & 13,780 & 0,508 & \\
X2 $(40 \%)$ & 10 & 12,570 & 0,604 & \\
X3 $(60 \%)$ & 10 & 11,500 & 0,533 & $<0,001$ \\
X4 $(80 \%)$ & 10 & 10,160 & 0,520 & \\
X5 (100\%) & 10 & 9,110 & 0,516 & \\
\hline
\end{tabular}

Berdasarkan tabel diatas dapat diketahui bahwa perbedaan nilai noise setelah dilakukan Rekonstruksi Iterative pada citra NCCT urography hasil uji beda dengan One Way Anova didapatkan nilai $\mathrm{p}<0,001(<0,005)$ yang berarti bahwa terdapat perbedaan yang bermakna nilai noise setelah dilakukan Rekonstruksi Iterative.

Pada penelitian ini, nilai noise mengalami penurunan seiring dengan peningkatan persentase Rekonstruksi Iterative yang digunakan pada citra NCCT urography. Pada penggunaan persentase Rekonstruksi Iterative 100\% didapatkan nilai rata-rata noise yang paling rendah yaitu 9,11. Menurut penulis, citra yang dihasilkan merupakan hasil dari penggunaan jumlah persentase Rekonstruksi Iterative untuk mereduksi noise pada citra baru yang dihasilkan. Noise yang paling rendah didapatkan pada penerapan Rekonstruksi Iterative $100 \%$ karena pada penerapan Rekonstruksi ini, forward projection data atau data awal digunakan secara keseluruhan (100\%) untuk dilakukan Rekonstruksi Iterative yaitu dengan dilakukan penggabungan dengan raw data tiruan (simulated projection data).

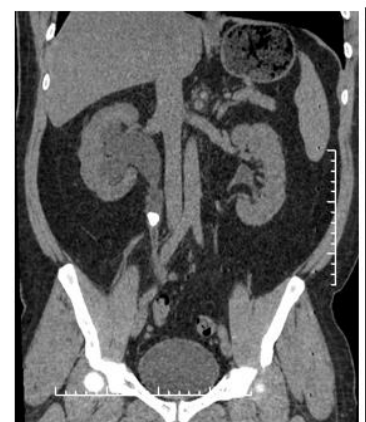

A

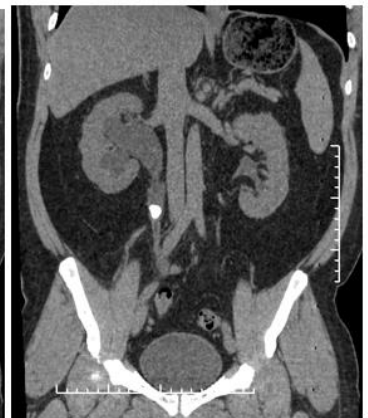

B

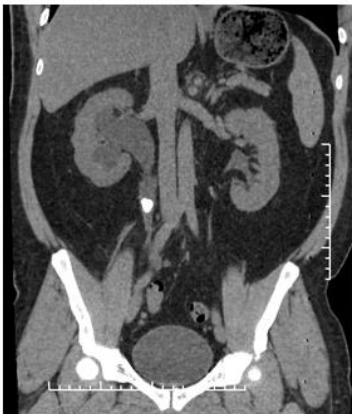

C

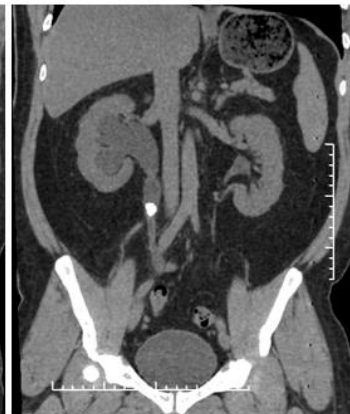

D

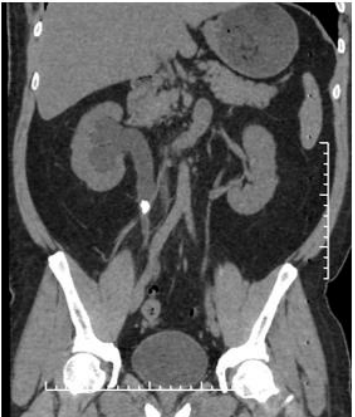

$\mathbf{E}$

Gambar 1 Citra NCCT Urography setelah dilakukan Rekonstruksi Iterative A) $20 \%$; B) $40 \%$; C) $60 \%$; D) $80 \%$ dan E) $100 \%$ 
Hasil penelitian ini didukung dengan penelitian sebelumnya bahwa, Rekonstruksi Iterative merupakan metode rekonstruksi algoritma pada CT Scan dengan prinsip dasar melakukan estimasi data untuk menghasilkan citra rekonstruksi dengan mengurangi noise 16,17. Penggunaan Rekonstruksi Iterative yang semakin tinggi, maka data awal citra CT Scan akan dilakukan rekontruksi korektif secara penuh dari data awal dengan intensif sehingga sinyal-sinyal yang tidak sesuai dengan estimasi sinyal pada objek akan dihilangkan ${ }^{8,17}$.

\section{SIMPULAN}

Berdasarkan Penelitian ini dapat disimpulkan bahwa penggunaan Rekonstruksi Iterative dapat mereduksi noise pada citra NCCT urography 9,386\% dibandingkan dengan Filtered Back Projection (FBP). Rekonstruksi Iterative mampu menurunkan noise dan meningkatkan kualitas citra NCCT urography.

\section{UCAPAN TERIMA KASIH}

Alhamdulillah peneliti ucapkan atas berkat Rahmat Allah SWT. Ucapan terima kasih kepada Orangtua, Istri dan saudara Catur Budi Saputra yang membantu dalam proses pengambilan data. Selanjutnya Terima kasih kepada Instalasi Radiologi RSI Sultan Agung Semarang yang telah memberikan izin dalam pengambilan data penelitian ini.

\section{DAFTAR PUSTAKA}

1. Joffe SA, Servaes S, Okon S, Horowitz M. Multi - Detector Row CT Urography in the Evaluation of. RSNA. Published online 2003:1441-1455.

2. Moussa SA, Mariapan P. Imaging of the Genitourinary System - Urolithiasis. First edit. (Morcos SK, Thomsen HS, eds.),; 2009.

3. Xiao-yun HU, Chun-hong HU, Xiang-ming F, Xuan-jun YAO, Lerner A, Hong-wei C. Practical value of intravenous urography combined with add-on. 2012;125(7):1287-1291. doi:10.3760/cma.j.issn.0366-6999.2012.07.018

4. Wang J, Lin W, Wei C, Chang C. Diagnostic Value of Unenhanced Computerized Tomography Urography in The Evaluation of Acute Renal Colic. Kaohsiung J Med Sci. 2003;19(10):503-508. doi:10.1016/S1607-551X(09)70498-X 
SANITAS: JURNAL TEKNOLOGI DAN SENI KESEHATANI

5. Hartman RP, Kawashima A, LeRoy AJ. Helical CT in The Diagnosis of Urolithiasis.; 2006.

6. Bombiński P, Warchoł S, Brzewski M, et al. Lower-dose CT urography ( CTU ) with iterative reconstruction technique in children - initial experience and examination protocol. Polish $J$ Radiol. Published online 2014:137-144. doi:10.12659/PJR.890729

7. Guzinski M, Waszczuk $Ł$, Marek JS. Head CT: Image quality improvement of posterior fossa and radiation dose reduction with ASiR - comparative studies of CT head examinations. Published online 2016. doi:10.1007/s00330-015-4183-4

8. Seeram E. Computed Tomography Physical Principles, Clinical Applications and Quality Control. Fourtth Ed.; 2016.

9. Bushberg JT, Seibert JA, Leidholdt EM, Boone JM. The Essential Physics for Medical Imaging.pdf. Published online 2003.

10. Sagara Y, Hara AK, Pavlicek W, Silva AC, Paden RG. Abdominal CT: Comparison of Low-Dose CT With Adaptive Statistical Iterative Reconstruction and RoutineDose CT With Filtered Back Projection in 53 Patients. Am J Radiol. 2010;(September):713-719. doi:10.2214/AJR.09.2989

11. Vardhanabhuti V, Loader RJ, Mitchell GR, Riordan RD, Roobottom CA. Image Quality Assessment of Standard- and Low-Dose Chest CT Using Filtered Back Projection, Adaptive Statistical Iterative Reconstruction, and Novel ModelBased Iterative Reconstruction Algorithms. Am J Radiol. 2013;(March):545-552. doi:10.2214/AJR.12.9424

12. Nagatani Y, Takahashi M, Murata K, et al. Lung nodule detection performance in five observers on computed tomography ( $\mathrm{CT}$ ) with adaptive iterative dose reduction using three-dimensional processing ( AIDR 3D ) in a Japanese multicenter study: Comparison between ultra-low-dose CT and low-dose CT. Eur $J$ Radiol. 2015;84(7):1401-1412. doi:10.1016/j.ejrad.2015.03.012

13. Sugiyono. Metode Penelitian Kuantitatif, Kualitatif Dan R \& D. Alfabeta; 2011.

14. Lemeshow S. SAMPLE SIZE DETERMINATION IN HEALTH STUDIES. Published online 1991.

15. Verdun FR, Racine D, Ott JG, Tapiovaara MJ, Toroi P, Bochud FO. Image quality in CT: From physical measurements to model observers. Phys Medica. 2015;31(8):823-843. doi:10.1016/j.ejmp.2015.08.007

16. Leipsic J, Labounty TM, Heilbron B, et al. Adaptive Statistical Iterative Reconstruction: Assessment of Image Noise and Image Quality in Coronary CT Angiography. Am J Radiol. 2010;(September). doi:10.2214/AJR.10.4285

17. Geyer LL, Schoepf UJ, Meinel FG, et al. State of the Art: Iterative CT Reconstruction Techniques. RSNA. 2015;276(2):339-357. 